\title{
Antibiotic resistance in Campylobacter and other diarrheal pathogens isolated from US military personnel deployed to Thailand in 2002-2004: a case-control study
}

Carl J. Mason ${ }^{1 *}$, Siriporn Sornsakrin ${ }^{1}$, Jessica C. Seidman², Apichai Srijan ${ }^{1}$, Oralak Serichantalergs ${ }^{1}$, Nucharee Thongsen ${ }^{1}$, Michael W. Ellis ${ }^{3}$, Viseth Ngauy ${ }^{4}$, Brett E. Swierczewski ${ }^{1}$ and Ladaporn Bodhidatta ${ }^{1}$

\begin{abstract}
Background: Campylobacter continues to be an important cause of diarrheal disease worldwide and a leading cause in Southeast Asia. Studies of US soldiers and marines deployed to Thailand for a 2 to 3 week field exercise provide a unique population in which to study traveler's diarrhea.

Methods: A case-control study of 217 deployed military personnel was conducted from 2002 through 2004. Of these, 155 subjects who presented to a field medical unit with acute diarrhea were enrolled as cases. These subjects referred an additional 62 diarrhea-free colleagues who served as controls. Frequencies of isolation of Campylobacter spp. and other enteric pathogens were compared in cases and controls, and antibiotic resistance of isolates was described.

Results: Of the 155 subjects with diarrhea, Campylobacter spp. was the most commonly identified pathogen, found in 54 (35\%) of the subjects, followed by non-typhoidal Salmonella species found in 36 (23\%) subjects. Of the 57 separate C. jejuni and C. coli isolates from these individuals, 51 (89\%) were resistant to ciprofloxacin by the disc diffusion method. Nearly one-third of the Campylobacter species were resistant to ampicillin and trimethoprimsulfamethoxazole. Resistance to azithromycin remained low at 2\% $(n=1)$.

Conclusions: The significant morbidity and marked fluoroquinolone resistance associated with Campylobacter infections in Thailand are important considerations for clinicians providing counseling on appropriate antibacterial regimens for civilian and military travelers.
\end{abstract}

Keywords: Campylobacter, Traveler's diarrhea, Military personnel, Cobra Gold, Thailand, Antibiotic resistance

\section{Background}

Acute infectious diarrhea poses a significant threat to international travelers and deployed military personnel particularly during travel in tropical regions where the risk of acquiring diarrhea is estimated to be $30-50 \%$ [1]. Although there are local and regional variations in etiology, the majority of traveler's diarrhea is caused by bacterial pathogens [2]. Globally, enterotoxigenic Escherichia coli (ETEC) are most frequently isolated from travelers with

\footnotetext{
* Correspondence: carlmason@icloud.com

'Armed Forces Research Institute of Medical Sciences, Bangkok 10400, Thailand

Full list of author information is available at the end of the article
}

diarrhea; however other organisms such as Campylobacter and Salmonella contribute significantly to the burden of traveler's diarrhea, especially in South East Asia and Thailand [3-7].

Campylobacter causes more severe and debilitating illness than most other causes of travelers' diarrhea $[6,8$, 9]. The clinical presentation of Campylobacter enteritis can range from a mild, watery diarrhea to a dysenteric disease with fecal leukocytes and frank blood [10]. Some strains are capable of eliciting a post-infectious polyneuropathy, Guillain-Barre Syndrome [11]. In both nonimmune and indigenous populations, Campylobacter resistance to standard treatment regimens has increased. 
Resistance of Campylobacter to ciprofloxacin was reported to be above $80 \%$ in Thailand in the 1990's [12].

Deployed US military personnel are a unique study population. Cobra Gold is a country-wide, multilateral military training exercise held annually in Thailand. It is well suited for diarrheal disease studies due to the availability of good laboratory support and a large, identifiable group of travelers with predictable schedules who can be identified and followed over a one month period [5]. Previous studies in US soldiers deployed to Thailand for this exercise showed Campylobacter was the leading cause of diarrhea [7-9, 13-15]. Here we report on the monitoring activities conducted during Cobra Gold 20022004 exercises. Periodic disease surveillance is critical for determining year-to-year variation in pathogen-specific etiologies, identifying the circulating strain serotypes, and monitoring drug resistance. Similar to a previous study [9], we have included a diarrhea-free control group in order to assess the etiologic importance of isolated stool pathogens including Campylobacter, Shigella, Salmonella, Vibrio, Aeromonas, Plesiomonas and diarrheagenic E. coli.

\section{Methods}

This study obtained scientific and ethical approval from the Walter Reed Army Institute of Research Human Use Review Committee. The study population consisted of US soldiers, sailors, and marines who participated in the Operation Cobra Gold 2002-2004. Field laboratories and data collection teams were established at each study site (Sa Kaeo in 2002; Prachuap Khirikhan in 2003; Chonburi in 2004 and Nakornratchasima in 2004). The purpose and availability of the study was explained to the staff of the units at the study site. Posters were placed throughout the study site. Personnel presenting to the field medical unit at the study site with acute diarrhea were recruited as cases. Acute diarrhea was defined as three or more loose stools in a 24-h period. Each control subject was an asymptomatic colleague referred by a case for potential participation. Exclusion criteria for control subjects included diarrhea, fevers, or use of antimicrobials in the prior week. The study was explained by team members and each subject provided signed informed consent. Names and social security numbers were used to ensure accurate reporting of findings to the military medical staff treating patients, but were not used during laboratory or data analysis.

Each subject provided a stool sample. Stool specimens were cultured on-site. Stool specimens were processed within $4 \mathrm{~h}$. Isolate identification and antibiotic susceptibility testing was done at the Armed Forces Research Institute of the Medical Sciences in Bangkok. Stool specimens were inoculated into MacConkey (MAC), Hektoen Enteric, thiosulfate-citrate-bile salts sucrose, modified semi-solid Rappaport-Vassiliadis (MSRV) media before and after enrichment in selenite $\mathrm{F}$, alkaline peptone water and buffer peptone water broths. All agar media and broths were incubated at $37{ }^{\circ} \mathrm{C}$ for $18-24 \mathrm{~h}$ except MSRV media which was incubated at $42{ }^{\circ} \mathrm{C}$ for $24 \mathrm{~h}$. Primary and secondary plating for Campylobacter was also performed. Six to 8 drops of fecal suspension were applied to $0.65 \mu \mathrm{m}$ sterile cellulose acetate membrane filters (Millipore, USA) centrally placed on the surface of Brucella agar (Difco, USA) with 5\% sheep blood plates. After a $30-\mathrm{min}$ incubation at room temperature to allow filtration, membranes were removed and the plates incubated at $37{ }^{\circ} \mathrm{C}$ under microaerobic conditions (generated by a Gas Pak) for $48 \mathrm{~h}$. In addition, approximately $0.5 \mathrm{ml}$ of the remaining fecal suspension was placed in Preston selective enrichment broth and incubated for $48 \mathrm{~h}$ at $37^{\circ} \mathrm{C}$ under microaerobic conditions prior to carrying out the membrane filtration technique described above.

Shigella, non-typhoidal Salmonella, Vibrio, Aeromonas and Plesiomonas shigelloides were identified by standard biochemical methods [16]. Shigella and Vibrio spp. were serotyped using Denka-Seiken antisera. Salmonella spp. was serogrouped using Serotest antiserum (S\&A Reagents Lab, Thailand). Up to five lactose fermenting and five non-lactose fermenting colonies of $E$. coli (as identified on MAC agar and confirmed by biochemical typing) were saved on Dorset egg yolk media slant. Diarrheagenic $E$. coli isolates were identified by hybridization with specific digoxigenin-labeled polynucleotide DNA probes: heat-labile toxin (LT), and heat-stable toxins STIa (STp) and STIb (STh) probes for Enterotoxigenic E. coli (ETEC) [17]; Bundle forming protein A (BfpA) and effacing and attaching (EAE) probes for Enteropathogenic E. coli (EPEC) $[18,19]$; and pCVD432 probe for Enteroaggregative E.coli (EAEC) [20]. Colonization factor antigens for ETEC isolates were identified by dot immunoblot assay [21-23].

Giardia/cryptosporidium detection was performed using commercial Prospect $\mathrm{T}^{\circledast}$ Microplate assay (AlexonTrend, USA). Stool samples were tested for rotavirus, adenovirus and astrovirus by a commercial ELISA test (R-Biopharm AG, Germany).

All isolates of Shigella, E. coli, Campylobacter, Vibrio, Aeromonas, P. shigelloides, and Salmonella were tested for antimicrobial susceptibility to ampicillin, azithromycin, ciprofloxacin, nalidixic acid, trimethoprim/sulfamethoxazole and tetracycline by the disc diffusion method as recommended by NCCLS [24, 25] using commercially prepared antibiotic discs (BD Diagnostic Systems, Sparks, MD, USA). Campylobacter isolates were tested for susceptibility to antimicrobial drugs using the disk diffusion assay with modifications. Because no standardized interpretive criteria existed for Campylobacter spp., the inhibition zone diameters were measured and interpreted following the disk manufacturer's instructions 
and compared against the Clinical and Laboratory Standards Institute (formerly NCCLS) standard guidelines for aerobic gram-negative bacilli to interpret the results as susceptible, intermediate, or resistant.

Risk Questionnaires regarding risk factors were completed by the study subjects. In all years, subjects were surveyed about travel history (including previous travel to Cobra Gold exercises, Thailand and South East Asia) and recent illness symptoms, and medication use. Risk Questionnaires from 2002 and 2003 asked about sources of food consumed (on-base: military dining facility, civilian establishment; off-base: street vendors, traditional Thai restaurants, and non-traditional restaurants (e.g. Pizza Hut)) and exposure to specific foods and drinks on- and off-base in the preceding five days.

Data were entered into an Epi-Info version 3.3 database. Statistical analysis was performed using IBM SPSS Statistics version 23, computed for chi-square tests/Fisher's exact tests, odds ratio and 95\% confidence interval (CI) by two-way tables and multivariate logistic regression and considered statistically significant using a two-tailed $p$-value $<0.05$.

\section{Results}

\section{Study population}

Over the three enrollment years, a total of 159 US soldiers or marines with acute diarrhea participated in the study as cases while only 66 of their asymptomatic colleagues participated as control subjects. Eight subjects (4 diarrhea cases and 4 non-diarrhea controls) had incomplete data and were excluded from analysis. The overall enrollment numbers were consistent from year to year and site to site. Nearly all volunteers were male, reflecting the demographics of the surveyed population, and most participants were junior in rank (Table 1).

\section{Organisms isolated}

Of 155 cases and 62 controls, C. jejuni, ETEC and $P$. shigelloides were isolated significantly more frequently from cases than controls $(p<0.01)$ (Table 2). Among the 54 cases positive for Campylobacter spp., C. jejuni was isolated from 45 (83\%) and C. coli was isolated from 10 (20\%); one case was positive for both species. Although isolation of diarrheagenic E. coli was not significantly associated with case status, subgroup analysis revealed 17 of the 18 ETEC isolations were from cases $(p=0.03)$. All of the 17 ETEC isolated from diarrheal cases were ST-ETEC and 1 LTST-ETEC was from nondiarrhea control. The colonization factors (CFs) of STETEC were characterized as CS6 (35\%), CS2,3 (6\%), PCFO166 (6\%) and unidentified CF (52\%). EPEC and EAEC isolation was similar between cases and controls. The frequency of non-typhoidal Salmonella isolation
Table 1 Numbers, locations and demographic data of diarrhea cases and controls during Operation Cobra Gold, 2002-2004

\begin{tabular}{llll}
\hline Description & Case & Control & Total \\
\hline Year & & & \\
2002 & 52 & 21 & 73 \\
2003 & 48 & 26 & 74 \\
2004 & 55 & 15 & 70 \\
Location & & & \\
Sa Kaeo, 2002 & 52 & 21 & 73 \\
Prachuap Khirikhan, 2003 & 48 & 26 & 74 \\
Chonburi, 2004 & 34 & 7 & 41 \\
Nakornratchasima, 2004 & 21 & 8 & 29 \\
Sex & & & \\
Male & 150 & 60 & 210 \\
Female & 5 & 2 & 7 \\
Grade Group & & & \\
Junior Enlisted (E1-E4) & 82 & 29 & 111 \\
Noncommissioned Officer (E5-E9) & 47 & 23 & 70 \\
Officer (O1 - O9) & 19 & 8 & 27 \\
Other & 7 & 2 & 9 \\
Total & 155 & 62 & 217 \\
\hline
\end{tabular}

was not significantly different between cases and controls.

Other potential etiologic agents of diarrhea were found infrequently. Seven of eight Vibrio parahaemolyticus and two of three Aeromonas spp. were isolated from cases. Shigella, Giardia, Cryptosporidium, rotavirus or astrovirus were not identified in either cases or controls during the the three study years. Adenovirus was detected in one case specimen from year 2004.

The odds of isolating any enteric pathogen were significantly greater for cases than controls $(p<0.01)$ and significantly more cases than controls provided specimens from which multiple pathogens could be detected $(p=0.01)$ (Table 2$)$. Nearly half (22 of 54) of case specimens positive for Campylobacter were also positive for at least one of the following pathogens: adenovirus, diarrheagenic E. coli, P. shigelloides, or Salmonella.

\section{Antimicrobial Susceptibility testing}

Resistance to multiple antibiotics was common among Campylobacter isolates found in approximately 95\% of both $C$. jejuni and C. coli isolates. Resistance to fluoroquinolones, ampicillin and trimethoprim/sulfamethoxazole was similar between the $C$. jejuni and $C$. coli isolates. Fluoroquinolone resistance was very common among the 57 Campylobacter isolates: 54 were resistant to nalidixic acid (95\%) and 51 (89\%) were resistant to ciprofloxacin (Table 3). One C. coli isolate was resistant to azithromycin. 
Table 2 Percentage of enteric pathogens isolated from diarrhea cases and controls during Operation Cobra Gold, 2002-2004

\begin{tabular}{|c|c|c|c|c|c|c|c|}
\hline \multirow{2}{*}{$\begin{array}{l}\text { Pathogen } \\
\text { Aeromonas spp. }\end{array}$} & \multicolumn{2}{|c|}{$\begin{array}{l}\text { Cases } n(\%) \\
(N=155)\end{array}$} & \multicolumn{2}{|c|}{$\begin{array}{l}\text { Controls } n(\%) \\
(N=62)\end{array}$} & \multicolumn{2}{|c|}{$\begin{array}{l}\text { Odds Ratio } \\
(95 \% \mathrm{Cl})\end{array}$} & \multirow{2}{*}{$\frac{p \text {-value }}{1.00}$} \\
\hline & 2 & (1) & 1 & (2) & 0.80 & $(0.07-8.96)$ & \\
\hline Campylobacter spp. & 54 & (35) & 2 & (3) & 16.04 & $(3.77-68.18)$ & $<0.01$ \\
\hline C. jejuni & 45 & (29) & 1 & (2) & 24.96 & (3.36-185.53) & $<0.01$ \\
\hline C. coli & 10 & (6) & 0 & & - & & 0.07 \\
\hline C. spp & 0 & & 1 & (2) & - & & 0.29 \\
\hline Diarrheagenic E. coli & 29 & (19) & 6 & (10) & 2.15 & $(0.84-5.47)$ & 0.15 \\
\hline ETEC & 17 & (11) & 1 & (2) & 7.51 & $(0.98-57.74)$ & 0.03 \\
\hline LTST & 0 & & 1 & (2) & - & & 0.29 \\
\hline ST & 17 & (11) & 0 & & - & & $<0.01$ \\
\hline EPEC & 11 & (7) & 4 & (6) & 1.11 & $(0.34-3.62)$ & 1.00 \\
\hline EAEC & 4 & (3) & 1 & (2) & 1.62 & $(0.18-14.75)$ & 1.00 \\
\hline P. shigelloides & 21 & (14) & 1 & (2) & 9.56 & $(1.26-72.70)$ & 0.01 \\
\hline Non-typhoidal Salmonella spp. & 36 & (23) & 10 & (16) & 1.57 & $(0.73-3.41)$ & 0.28 \\
\hline V. parahaemolyticus & 7 & (5) & 1 & (2) & 2.89 & $(0.35-23.95)$ & 0.45 \\
\hline Adenovirus & 1 & (0.6) & 0 & & - & & 1.00 \\
\hline No Enteric Pathogen Identified & 45 & (29) & 47 & (76) & 0.13 & $(0.07-0.26)$ & $<0.01$ \\
\hline$>1$ Enteric Pathogen Detected & 36 & (23) & 5 & (8) & 3.45 & $(1.29-9.26)$ & 0.01 \\
\hline
\end{tabular}

${ }^{\text {aFisher's exact }}$

All bacterial species except for Campylobacter were susceptible to ciprofloxacin. Regarding diarrheagenic E.coli, all EAEC isolates were completely resistant to ampicillin, tetracycline and trimethoprim/sulfamethoxazole. A greater percentage of EPEC isolates were resistant to ampicillin, tetracycline, trimethoprim/sulfamethoxazole and nalidixic acid than ETEC ( 81 vs $42 \%, 81$ vs $37 \%, 75$ vs $37 \%$, $38 \%$ vs $5 \%$, respectively). Resistance to azithromycin was seen only among EAEC (40\%) and EPEC isolates (13\%). All eight $V$. parahaemolyticus isolates were resistant to ampicillin and had no other antibiotic resistance.

\section{Questionnaire data}

Cases who were positive for Campylobacter were more likely to self-report fever, muscle aches $(p<0.01)$ and headache $(p=0.02)$ than cases negative for Campylobacter

Table 3 Number and percent of enteric pathogen isolates resistant to selected antibiotics ${ }^{a}$

\begin{tabular}{|c|c|c|c|c|c|c|c|c|}
\hline \multirow[t]{2}{*}{ Pathogen } & \multirow[t]{2}{*}{ Number of isolates } & \multicolumn{7}{|c|}{ Percent resistance } \\
\hline & & $\mathrm{AM}$ & AZM & CIP & NA & SXT & TE & $\geq 2$ antibiotics \\
\hline Aeromonas spp. & 3 & 100 & 0 & 0 & 67 & 0 & 67 & 67 \\
\hline Campylobacter spp. & 57 & 32 & 2 & 89 & 95 & 19 & 68 & 95 \\
\hline C. jejuni & 47 & 34 & 0 & 89 & 94 & 19 & 68 & 96 \\
\hline C. coli & 10 & 20 & 10 & 90 & 100 & 20 & 70 & 90 \\
\hline Diarrheagenic E. coli & 40 & 65 & 10 & 0 & 18 & 60 & 63 & 65 \\
\hline ETEC & 19 & 42 & 0 & 0 & 5 & 37 & 37 & 42 \\
\hline EPEC & 16 & 81 & 13 & 0 & 38 & 75 & 81 & 81 \\
\hline EAEC & 5 & 100 & 40 & 0 & 0 & 100 & 100 & 100 \\
\hline P. shigelloides & 22 & 50 & 0 & 0 & 27 & 27 & 68 & 64 \\
\hline Non-typhoidal Salmonella spp. & 54 & 33 & 6 & 0 & 35 & 24 & 63 & 48 \\
\hline V. parahaemolyticus & 8 & 100 & 0 & 0 & 0 & 0 & 0 & 0 \\
\hline
\end{tabular}


isolation (Table 4). However, after adjustment by logistic regression, only fever and headache remained significantly associated with Campylobacter isolation in cases (Table 4). Those reporting abdominal cramps, nausea and vomiting were not significantly more likely to be Campylobacter positive. There were no other statistically significant associations between any of the enteric pathogens detected and self-reported symptoms.

A comparison of traveler's diarrhea risk factors; highrisk foods, source of foods, and previous travels to Cobra Gold, Thailand or Southeast Asia showed no statistically significant difference between cases and controls. Among cases, positivity for Campylobacter was not statistically significantly associated with previous travel to Thailand, Southeast Asia, any other overseas location, or previous participation in Cobra Gold exercises (data not shown). Based on responses to the 2002 and 2003 questionnaires, there were no significant associations with all foods and food sources identified (data not shown).

\section{Discussion}

This study focused on determining the diarrhea etiology and antimicrobial susceptibility pattern among US military deployed to Thailand 2002-2004. Despite the differing locations and timeframes studied, Campylobacter spp. predominated and was identified in 35\% of diarrhea cases, followed by non-typhoidal Salmonella spp., diarrheagenic E.coli, P. shigelloides, V. parahaemolyticus and Aeromonas spp. While other pathogens were identified in both cases and controls, the isolation of $C$. jejuni, STETEC and $P$. shigelloides was significantly associated with symptomatic infections. Similar prior studies [5, 13-15], and a systematic review of travelers' diarrhea etiology conducted during 1990 and 2005 reported a prevalence of Campylobacter of $23.9 \%$ for Southeast Asia [26]. In a recent diarrheal etiology study of a US military exercise in the Philippines in 2014 showed 4 of 7 diarrhea stool samples (57\%) were positive for Campylobacter spp. [27]. Campylobacter continues to be the leading cause of diarrhea in US military personnel deployed to Thailand or Southeast Asia.
Fluoroquinolone resistance among Campylobacter isolated from this population is high but consistent with the trend of increasing prevalence over the preceding 15 years: $76 \%$ in 1994, 84\% in 1995, and 96\% in 1998 in Campylobacter isolated from similar populations $[8,10]$. Additionally, two hospital based traveler's diarrhea studies in Bangkok, Thailand found Campylobacter resistance to ciprofloxacin and nalidixic acid in $83 \%$ and $89 \%$ of isolates in 2001-2003 [28], and in 91\% and 93\% of isolates in 2012-2014, respectively [Unpublished data].

Interestingly, none of the other diarrheal pathogens isolated during this study were resistant to ciprofloxacin, despite a moderate frequency of nalidixic acid resistance. The observed level of resistance to nalidixic acid in nontyphoidal Salmonella isolates in this study is congruent with a slow but steady increase in prevalence previously reported of $1 \%$ in $1991-1992,4 \%$ in $1993-94,9 \%$ in 1995 [12], $21 \%$ in 1996-1999 [29], and finally to $35 \%$ in 2002-2004 in this study.

The majority of the diarrheal pathogens isolated in this study showed a moderate frequency of resistance to ampicillin, trimethoprim/sulfamethoxazole and tetracycline, but a low frequency of resistance to azithromycin. The level of resistance to azithromycin seen in the Campylobacter isolates is consistent with previous reports [12]. Only one $C$. coli isolate was resistant to azithromycin, however, fewer than 20\% of all Campylobacter isolates were identified as $C$. coli. Fortunately, this organism is still a relatively infrequent cause of acute diarrheal illness. All $V$. parahaemolyticus isolates were resistant to ampicillin but were otherwise susceptible to the other antibiotics tested. Among the antibiotics tested, azithromycin had the broadest spectrum of activity against the pathogens isolated in this study.

However, for diarrhea caused by Campylobacter spp., azithromycin was the best available therapeutic agent due to the high level of fluoroquinolone resistance. The American College of Gastroenterology (ACG) Clinical Guideline currently recommends azithromycin for empiric use as first line therapy to treat travelers' diarrhea in Southeast Asia [30]. Since the prevalence of resistance to azithromycin was low in the other isolated pathogens, treatment with

Table 4 Association between Campylobacter isolation and self-reported symptoms among diarrhea cases

\begin{tabular}{|c|c|c|c|c|c|c|c|c|c|c|}
\hline \multirow{2}{*}{$\begin{array}{l}\text { Symptom } \\
\text { Abdominal cramps }\end{array}$} & \multicolumn{2}{|c|}{$\begin{array}{l}\text { Campylobacter isolated } \mathrm{n}(\%) \\
N=54\end{array}$} & \multicolumn{2}{|c|}{$\begin{array}{l}\text { Campylobacter not isolated } \mathrm{n}(\%) \\
N=101\end{array}$} & \multicolumn{2}{|c|}{$\begin{array}{l}\text { Odds Ratio } \\
(95 \% \mathrm{Cl})\end{array}$} & \multirow{2}{*}{$\begin{array}{c}p \text {-value } \\
0.70\end{array}$} & \multicolumn{2}{|c|}{$\begin{array}{l}\text { Adjusted Odds Ratio } \\
(95 \% \mathrm{Cl})^{*}\end{array}$} & \multirow[t]{2}{*}{$p$-value } \\
\hline & 41 & (76) & 73 & (72) & 1.21 & $(0.57,2.59)$ & & & & \\
\hline Fever & 40 & (74) & 24 & (24) & 9.17 & $(4.28,19.64)$ & $<0.01$ & 9.96 & $(4.50,22.00)$ & $<0.01$ \\
\hline Nausea & $36 / 53$ & (68) & 53 & (52) & 1.92 & $(0.96,3.85)$ & 0.09 & & & \\
\hline Vomiting & 19 & (35) & 23 & (23) & 1.84 & $(0.89,3.81)$ & 0.13 & & & \\
\hline Muscle aches & 31 & (57) & 32 & (32) & 2.91 & $(1.47,5.76)$ & $<0.01$ & & & \\
\hline Headache & 5 & (9) & 1 & (1) & 10.20 & $(1.16,89.73)$ & 0.02 & 15.41 & $(1.48,160.4)$ & 0.02 \\
\hline
\end{tabular}

*Final model from multivariate logistic regression removing least significant variable stepwise until $p<0.1$ for all retained variables 
azithromycin would still be effective, even in nonCampylobacter diarrheas accompanied by fever or in mixed infections. Continued close monitoring of resistance to azithromycin is essential to maintain effective treatment guidelines.

Limitations of this study result include observation design without an a priori sample size calculation. As the control subjects were selected by cases to have similar exposures, the limited number of enrolled controls may not be truly representative of the population at risk. In addition, controls could potentially develop diarrhea within 2 to 3 days of enrolment weakening the association between specific pathogens and diarrhea. In this study, we also did not test for Norovirus an important cause of travelers' diarrhea. Despite these limitations and the age of the data, the information on diarrhea etiology and antimicrobial susceptibility as well as disease association remain useful.

\section{Conclusions}

The frequency and severity of traveler's diarrhea due to Campylobacter, coupled with its high rate of fluoroquinolone resistance, are important considerations for clinicians providing advice regarding antibacterial prophylaxis and treatment for civilian and military travelers. The low level of azithromycin resistance observed in this study supports its empiric use for treatment of diarrhea cases among travelers from the US to Thailand.

\section{Abbreviations \\ CF: Colonization factor; EAEC: Enteroaggregative E.coli; \\ EPEC: Enteropathogenic E. coli; ETEC: Enterotoxigenic E. coli; LT: Heat-labile enterotoxin; MAC: MacConkey; MSRV: Modified semi-solid Rappaport- Vassiliadis; ST: Heat-stable enterotoxin}

\section{Acknowledgements}

The authors thank Bryan L. Smith, Michael Lewis, Rodney L. Coldren for their participation in study execution and the technicians, nurses, and professional staff of the Armed Forces Research Institute of Medical Sciences in Bangkok for their devoted microbiological expertise and assistance with collection of specimens and data processing.

\section{Funding}

Financial support for this study was provided by the US Department of Defence Global Emerging Infections Surveillance and Response System.

\section{Availability of data and materials}

The data that support the findings of this study are available with permission of AFRIMS.

\section{Authors' contributions}

CM conceived of the study, participated in the design, coordination and execution, the acquisition of data, assisted with the interpretation of data and drafting of the manuscript. SS and JS were primarily responsible for the analysis and interpretation of data and preparation of the final draft of the manuscript. AS participated in pathogen isolation and workup and in oversight of the microbiological laboratory. OS participated by performing advanced molecular characterizations of the isolates and in identification of parasitic and viral pathogens. NT participated in manuscript preparation, design and the maintenance of the study database and statistical analysis. ME participated in study execution and data acquisition. VN participated in study execution and data acquisition. BS participated in reviewing the manuscript LB participated in statistical analysis, interpretation of data and preparation and reviewing of the final draft of the manuscript. All authors reviewed, edited, and approved the final manuscript.

\section{Authors' information}

The opinions and statements contained within this article are the ones of the authors and are not to be construed as official or reflecting the views of AFRIMS, the US Army or Department of Defence.

\section{Ethics approval and consent to participate}

The study protocols were approved by the Institutional Review Board of Walter Reed Army Institute of Research (WRAIR IRB) as human subject research in compliance with the Helsinki Declaration guidelines. Written informed consent was obtained from each potential subject prior to participation in the study.

\section{Consent for publication}

Not applicable. No individual data is presented. All results include aggregate data.

\section{Competing interests}

The authors declare that they have no competing interests.

\section{Publisher's Note}

Springer Nature remains neutral with regard to jurisdictional claims in published maps and institutional affiliations.

\section{Author details}

'Armed Forces Research Institute of Medical Sciences, Bangkok 10400, Thailand. ${ }^{2}$ Fogarty International Center, National Institutes of Health, Bethesda, MD 20892, USA. ${ }^{3}$ Department of Medicine, University of Toledo College of Medicine and Life Sciences, Toledo, OH 43606, USA. ${ }^{4}$ Department of Medicine, Tripler Army Medical Center, Honolulu, HI 96859, USA.

Received: 10 April 2017 Accepted: 19 June 2017

Published online: 05 July 2017

\section{References}

1. DuPont HL. Travelers' diarrhea: antimicrobial therapy and chemoprevention. Nat Clin Pract Gastroenterol Hepatol. 2005;2:191-8.

2. Greenwood Z, Black J, Weld L, O'Brien D, Leder K, Von Sonnenburg F, et al. Gastrointestinal infection among international travelers globally. J Travel Med. 2008;15:221-8.

3. Gascon J. Epidemiology, etiology and pathophysiology of traveler's diarrhea. Digestion. 2006;73 Suppl 1:102-8.

4. Bourgeois AL, Gardiner CH, Thornton SA, Batchelor RA, Burr DH, Escamilla $J$, et al. Etiology of acute diarrhea among United States military personnel deployed to South America and west Africa. Am J Trop Med Hyg. 1993;48: 243-8.

5. Walz SE, Baqar S, Beecham HJ, Echeverria P, LeBron C, McCarthy M, et al. Pre-exposure anti-Campylobacter jejuni immunoglobulin a levels associated with reduced risk of Campylobacter diarrhea in adults traveling to Thailand. Am J Trop Med Hyg. 2001;65:652-6.

6. Beecham HJ, LeBron C, Echeverria P. Short report: impact of traveler's diarrhea on United States troops deployed to Thailand. Am J Trop Med Hyg. 1997;57:699-701.

7. Tribble DR, Sanders JW, Pang LW, Mason C, Pitarangsi C, Baqar S, et al. Traveler's diarrhea in Thailand: randomized, double-blind trial comparing single-dose and 3-day azithromycin-based regimens with a 3-day levofloxacin regimen. Clin Infect Dis. 2007;44:338-46.

8. Tribble DR, Baqar S, Pang LW, Mason C, Houng HS, Pitarangsi C, et al. Diagnostic approach to acute diarrheal illness in a military population on training exercises in Thailand, a region of campylobacter hyperendemicity. J Clin Microbiol. 2008;46:1418-25.

9. Sanders JW, Isenbarger DW, Walz SE, Pang LW, Scott DA, Tamminga C, et al. An observational clinic-based study of diarrheal illness in deployed United States military personnel in Thailand: presentation and outcome of Campylobacter infection. Am J Trop Med Hyg. 2002;67:533-8.

10. Allos BM, Blaser MJ. Campylobacter jejuni and the expanding spectrum of related infections. Clin Infect Dis. 1995;20:1092-9.

11. Nachamkin I, Allos B, Ho T. Campylobacter species and Guillain-Barre syndrome. Clin Microbiol Rev. 1998;11:555-67.

12. Hoge CW, Gambel JM, Srijan A, Pitarangsi C, Echeverria P. Trends in antibiotic resistance among diarrheal pathogens isolated in Thailand over 15 years. Clin Infect Dis. 1998;26:341-5. 
13. Petruccelli BP, Murphy GS, Sanchez JL, Walz SE, DeFraites R, Gelnett J, et al. Treatment of traveler's diarrhea with ciprofloxacin and loperamide. J Infect Dis. 1992;165:557-60.

14. Kuschner RA, Trofa AF, Thomas RJ, Hoge CW, Pitarangsi C, Amato S, et al. Use of azithromycin for the treatment of Campylobacter enteritis in travelers to Thailand, an area where ciprofloxacin resistance is prevalent. Clin Infect Dis. 1995;21:536-41.

15. Murphy GS, Jr., Echeverria P, Jackson LR, Arness MK, LeBron C, Pitarangsi C. Ciprofloxacin- and azithromycin-resistant Campylobacter causing traveler's diarrhea in U.S. troops deployed to Thailand in 1994. Clin Infect Dis. 1996;22: 868-9.

16. Isenberg HD. Essential Procedures for Clinical Microbiology. Washington: ASM Press; 1998

17. Sommerfelt H, Grewal HM, Bhan MK. Simplified and accurate nonradioactive polynucleotide gene probe assay for identification of enterotoxigenic Escherichia coli. J Clin Microbiol. 1990;28:49-54.

18. Girón JA, Donnenberg MS, Martin WC, Jarvis KG, Kaper JB. Distribution of the bundle-forming pilus structural gene (bfpA) among enteropathogenic Escherichia coli. J Infect Dis. 1993;168:1037-41.

19. Jerse AE, Yu J, Tall BD, Kaper JB. A genetic locus of enteropathogenic Escherichia coli necessary for the production of attaching and effacing lesions on tissue culture cells. Proc Natl Acad Sci U S A. 1990;87:7839-43.

20. Baudry B, Savarino SJ, Vial P, Kaper JB, Levine MM. A sensitive and specific DNA probe to identify enteroaggregative Escherichia coli, a recently discovered diarrheal pathogen. J Infect Dis. 1990;161:1249-51.

21. Lopez-Vidal Y, Klemm P, Svennerholm AM. Monoclonal antibodies against different epitopes on colonization factor antigen I of enterotoxin-producing Escherichia coli. J Clin Microbiol. 1988;26:1967-72.

22. Lopez-Vidal Y, Svennerholm AM. Monoclonal antibodies against the different subcomponents of colonization factor antigen II of enterotoxigenic Escherichia coli. J Clin Microbiol. 1990;28:1906-12.

23. Viboud GI, Binsztein N, Svennerholm AM. Characterization of monoclonal antibodies against putative colonization factors of enterotoxigenic Escherichia coli and their use in anepidemiological study. J Clin Microbiol. 1993;31:558-64.

24. CLSI. Performance Standards for Antimicrobial Disk Susceptibility Tests; Approved Standard-Seventh edition. CLSI document M02-A07. Wayne: Clinical and Laboratory Standards Institute; 2000

25. CLSI. Performance Standards for Antimicrobial Disk Susceptibility Testing; Twelfth Informational Supplement. CLSI document M100-S12. Wayne: Clinical and Laboratory Standards Institute; 2002.

26. Riddle MS, Sanders JW, Putnam SD, Tribble DR. Incidence, etiology, and impact of diarrhea among long-term travelers (US military and similar populations): a systematic review. Am J Trop Med Hyg. 2006;74:891-900.

27. Velasco JM, Valderamat MT, Nogrado K, Wongstitwilairoong T, Swierczewski $B$, Bodhidatta $L$, et al. Diarrheal and respiratory illness surveillance during US-RP Balikatan 2014. MSMR. 2015;22:20-3.

28. Serichantalergs O, Pootong P, Dalsgaard A, Bodhidatta L, Guerry P, Tribble $\mathrm{DR}$, et al. PFGE, Lior serotype, and antimicrobial resistance patterns among Campylobacter jejuni isolated from travelers and US military personnel with acute diarrhea in Thailand, 1998-2003. Gut Pathog. 2010;2:15.

29. Isenbarger DW, Hoge CW, Srijan A, Pitarangsi C, Vithayasai N, Bodhidatta L, et al. Comparative antibiotic resistance of diarrheal pathogens from Vietnam and Thailand, 1996-1999. Emerg Infect Dis. 2002;8:175-80.

30. Riddle MS, DuPont HL, Connor BA. ACG Clinical guideline: diagnosis, treatment, and prevention of acute diarrheal infections in adults. Am J Gastroenterol. 2016;111:602-22

\section{Submit your next manuscript to BioMed Central and we will help you at every step:}

- We accept pre-submission inquiries

- Our selector tool helps you to find the most relevant journal

- We provide round the clock customer support

- Convenient online submission

- Thorough peer review

- Inclusion in PubMed and all major indexing services

- Maximum visibility for your research

Submit your manuscript at www.biomedcentral.com/submit
Biomed Central 